\title{
La traducción de J.G. Herder al alemán del romance Abenámar o Die Herrlichkeit Granada's
}

\author{
Paloma García Bravo \\ Universidad Complutense de Madrid \\ palgarcbravo@yahoo.es
}

Recibido: 18 de septiembre de 2010

Aceptado: 15 de diciembre de 2010

\section{RESUMEN}

En el siguiente artículo presentamos un estudio crítico comparativo sobre la primera traducción rimada al alemán del romance fronterizo "Abenámar" (1778) realizada por el filósofo alemán J.G. Herder. La temprana aparición en la Alemania del Sturm und Drang de este tipo de composiciones viene a avalar las teorías históricas, lingüísticas etnológicas y literarias del gran erudito alemán en un intento por ofrecer al lector alemán las formas de vida, de ser y de pensar de otros pueblos y otros tiempos, en consonancia con las ideas del espíritu romántico y prerromántico. A pesar de que la traducción parece que se realizó desde una fuente francesa, Herder logra captar plenamente el ambiente de mestizaje hispano-árabe medieval y reproducir un tipo de estrofa que enriquecería los metros alemanes.

Palabras clave: Traducción literaria, romances, Abenámar, J.G.Herder.

J.G. Herder's translation into German of the border ballad Abenámar or Die Herrlichkeit Granada's

\begin{abstract}
This article introduces a critical comment on the first rhymed verse translation of the Spanish border ballad, Abenamar, into German initially performed by German Scholar and Philosopher, J.G. Herder. This early Sturm und Drang publication illustrates Herder's historic, linguistic and ethnological theories and its purpose, in accordance with the first Romantic theories, was to give the German public an insight into the lives, identities and mentalities of another people from another time. In spite of the fact that this translation came from a French source, Herder succeeded in captivating the Spanish-Arabic fusion atmosphere as well as reproducing an enhanced German rhymed verse version of the initial works.
\end{abstract}

Key words: Literary translation, Spanish border ballad, Abenámar, J.G. Herder. 
Sumario: 1. Introducción. 2. Trasfondo histórico e ideológico del Sturm und Drang. 3. La figura de J.G. Herder y la gestación de su obra. 4. Volkslied alemanes y romances españoles: las fuentes de Herder. 5. La confluencia cultural en Abenamar o Die Herrlichkeit Granada's. 6. Estudio comparativo. 7. Conclusión.

\section{Introducción}

La temprana aparición en lengua alemana de la primera traducción rimada al alemán del romance Abenámar (1788) viene a avalar las teorías históricas, lingüísticas y etnológicas de Herder, en un intento por comprender y presentar al lector alemán las formas de vida, de ser y de pensar de otros pueblos y otros tiempos. Aunque, como era frecuente en la época, la traducción al alemán parece que se realiza, al menos parcialmente, desde una fuente francesa, Herder logra captar plenamente el ambiente medieval de mestizaje hispano-árabe presente en el romance y reproducir un tipo de estrofa que vendría a enriquecer los metros alemanes.

\section{Trasfondo histórico e ideológico del Sturm und Drang}

Los inicios del romanticismo bajo el significativo nombre de Sturm und Drang representan el prototipo de la reacción ideológica y cultural contra el status quo anterior. El nuevo movimiento ideológico y literario (1767-1785) coincide parcialmente con una época de revoluciones que se suceden entre 1789 y 1830 caracterizada por las reformas contra el Absolutismo Ilustrado (Allgemeines Landrecht, 1794) que iban a propiciar cambios en el estado y en la sociedad. Los hechos histórico-políticos llevan consigo una revulsión de las conciencias que tratan de indagar en todo lo que de natural hay en el hombre (sentimientos, ideas e impulsos), en clara oposición con el racionalismo de la Ilustración todavía presente.

El movimiento literario tiene como telón de fondo histórico (Negro Pavón 1982: 34-37) el Despotismo Ilustrado instaurado en Alemania bajo el reinado de Federico II de Prusia en conflicto con otras potencias germanas y europeos.

Merece ser mencionado el Edicto de Tolerancia de José II (1781) con la imposición del alemán en todo el reino. En 1786 muere Federico II de Prusia y comienza la Revolución Francesa que altera el orden político existente. Entre 1796 y 1798 Napoleón logra imponer su influencia con la consiguiente reorganización de los territorios alemanes .En 1804 se extingue oficialmente el Heiliges Römisches Reich Deutscher Nation, mientras Francisco I es proclamado káiser en Austria.

En el terreno cultural, aunque Gottsched intentaba desde 1740 afrancesar la literatura alemana, aparecen El Mesías de Klopstock y Miss Sara Sampson de Lessing (1770). Posteriormente verán la luz las primeras obras de Goethe (1770-1780). Kant publica la Crítica del juicio (1790), Niebuhr crea la nueva historiografía alemana con su Historia Romana y Savigni publica su famosa Historia del Derecho Romano en 1815. Por lo que respecta a la filosofía, Hegel inicia el idealismo dialéctico con su Wissenschaft der Logik. 
La relación entre la literatura y los cambios sociales desembocan en un nuevo concepto y en una nueva práctica de la literatura. La historia de la humanidad se concibe como la realización de un plan divino dentro de un panteísmo dinámico. En este sentido, se cree que el arte no es un medio para alcanzar un fin, sino Offenbarung o revelación. De acuerdo con la concepción filosófica de J.G.Hamann (17301788), contemporáneo de Kant y propulsor del romanticismo, el sentimiento y el estado anímico están dotados de una fuerza creadora que se manifiesta en la lengua en tanto que fuente de conocimiento, y se hace patente en la creación poética, ideas recogidas posteriormente por Schiller y Winckelmann. Para Hamann la lengua poética es igual al sonido de la naturaleza ya que tanto esta última como el poeta se realizan en la creación. Por ello la concepción simbólica y genial del arte no persigue más fin que el despertar del principio, ni más placer que su sentido simbólico. Se establece una identidad entre la poética del genio y la de las vivencias (Frenzel 1977:202).

El Sturm und Drang o prerromanticismo alemán arranca con los Fragmenten (1767) de Herder, figura con la que se considera indisociable. Debido a los grandes autores que participan en su gestación y a la valoración del subjetivismo y del genio creativo del artista, esta época ha sido denominada Geniezeit o Genieperiode. Herder define el genio como Urkraft o fuerza primigenia, Erfinder o elemento descubridor, Original o elemento originario. Lavater lo considera Aussprache unaussprachlicher Dinge y Licht der Welt. En este sentido, Mendelsohn afirma que "Das Genie kann den Mangel der Exempel ersetzen aber der Mangel des Genie ist unersetztlich”. Young puntualiza dentro de una poética de la libertad que „Regeln sind wie Krücken, eine notwendige Hilfe für den Lehman, aber ein Hindernis für den Gesunden". Gerstemberg opina "Das Genie geht nach der Ordnung der Natur vor dem Geschmack her"(Frenzel 1977). Por lo tanto, encontramos un marcado sesgo nacional, por lo que se cree que la latinización de la lengua alemana destruye su identidad. El propio Herder escribe a este respecto: "Je entscheidener unsere Werke deutsch und modern sind, um so verwändter werden sie den Griechen sein”; „Was uns ihnen gleich machen kann, ist allein die gleiche unbefangene geniale Schöpferkraft".

Por otro lado, el pesimismo histórico y religioso de Rousseau se convertirá en una filosofía cultural optimista en la figura de Herder. Desde el punto de vista de la propia creación poética, los hombres del Sturm und Drang reciben la influencia inglesa, personificada en una serie de autores y de obras en las que encontramos la genialidad de lo natural entendida como predisposición instintiva que sirve de estímulo para la creación o recreación de las Volkslieder de Herder o de Goethe partiendo de sus propias raíces. El modelo a seguir es Shakespeare que representa la ruptura de las unidades del teatro clásico, las escenas populares sueltas, la mezcla de lo cómico y lo trágico y la escritura en prosa, rasgos que encontramos también en el teatro de nuestro Lope de Vega y, posteriormente, en el alemán Lenz.

Para los hombres del Sturm und Drang la naturaleza se encuentra divinizada, lo que les lleva al optimismo y al idealismo. De ahí que identifiquen al hombre culto con el hombre natural. Asimismo reivindican la oposición entre la infinitud de la naturaleza y de la vida y el valor de lo infinito, de la realidad, dentro del espíritu de 
un sentimiento vital fáustico. La vida adquiere el sentido de superación de la propia conciencia del individuo. La historia de la humanidad se concibe como la realización de un plan divino dentro de un panteísmo dinámico.

\section{La figura de J. G. Herder (1744-1803) y la gestación de su obra}

El filósofo, teólogo y autor alemán forma parte junto con su condiscípulo Hamman y su maestro Kant, del triunvirato intelectual más importante de la Prusia oriental del siglo XVIII. La influencia de Herder en el Romanticismo resultó decisiva, ante todo, en lo que respecta a su interés por la Edad Media y por la literatura popular. Asimismo tuvo una repercusión fundamental en las posteriores teorías lingüísticas, antropológicas, teológicas, literarias e históricas durante todo el siglo XIX. Se ha visto en él el mayor impulsor espiritual de la historia alemana.

Herder ${ }^{1}$ nació en un ambiente familiar pietista cerca de Königsberg, ciudad en la que estudió Teología y Filosofía (1762-1764) y conoció a Kant y a Hamann. Tras la culminación de sus estudios se trasladó a Riga desde donde emprendió un prolongado viaje por Europa, experiencia que supuso una nueva interpretación del sentido de la vida (Killy 1988-1993: 232-238). De esta época procede su primera obra Über die neuere deutsche Literatur. Fragment, en la que defiende la idea de que la literatura alemana sólo puede alcanzar el rango de literatura clásica mediante la consideración consciente de la propia lengua alemana, alejada de influencias francesas e inglesas. Las experiencias acumuladas en su periplo europeo y en el viaje que emprende en 1769 a Francia quedan reflejadas en su Journal meiner Reise im Jahre 1769. Poco antes y en el mismo año había publicado Kritische Wälder oder Betrachtungen, die Wissenschaft und Kunst des Schönen betreffend.

En 1772 la Academia de las Ciencias de Berlín le otorga un premio por su obra Abhandlung über den Ursprung der Sprache, en la que explica el origen de las lenguas nacionales y su desarrollo basándose en las diferentes condiciones geográficas, climáticas y sociales de los distintos pueblos, y defiende la tesis del origen humano de la lengua, instrumento de toda manifestación cultural, oponiéndose al origen divino que le confería Hamann. Esta obra encuentra su continuación en la serie de escritos Von deutscher Art und Kunst, einige fliegende Blätter que se caracteriza por la admiración que despiertan en el autor alemán las literaturas nacionales genuinas, especialmente, la literatura popular alemana de la Edad Media.

Con Auszug aus einem Briefwechsel über Ossian und die Lieder alter Völker y Shakespeare muestra su reconocimiento por Shakespeare y Homero. A Herder le debemos el descubrimiento del espíritu del pueblo (Idee des Volksgeistes) que eleva a la categoría de identidad cultural, responsable de la expresión lingüística y literaria de una nación y agente fundamental de la historia, tal como aparece en su obra Auch eine Philosophie der Geschichte zur Bildung der Menschheit (1774). La his-

\footnotetext{
${ }^{1}$ Herder, Johann Gottfried/Biographie - Zeno.org http://www.zeno.org/Literatur/M/Herder, +Johann+ Gottfried/Biographie
} 
toria natural y la historia de la humanidad responden a las mismas leyes, de forma que los impulsos del hombre contra la naturaleza humana pueden verse restablecidos, lo que constituye la piedra angular para entender el desarrollo del progreso de la humanidad, idea que influiría en la filosofía de Hegel.

Herder entiende por "pueblo" una unidad espiritual y anímica, un organismo vivo que nace, crece, florece, madura y se extingue, y que manifiesta su espíritu en su religión, su música y su literatura. El desarrollo de las cosas proviene de Dios, raíz eterna e infinita de todo ser, pero cada pueblo es portador de una individualidad inimitable y la poesía popular representa la expresión de un mundo espiritual y anímico determinado. "Volk heisst nicht der Pöbel auf den Gassen, das singt und dichtet niemals, sondern schreit und verstummelt"2. En su obra Älteste Urkunde des Menschengeschlechts considera la historia de la creación como un mito literario.

En el año 1776 Herder se traslada a Weimar. En 1778 aparecen Lieder der Liebe. Die ältesten und schönsten aus dem Morgenlande. Nebst 44 alte Minnelieder, Volkslieder, posteriormente con el título de Stimmmen der Völker, con las que pretendía llamar la atención sobre las características de la poesía popular de las distintas naciones. Posteriormente Herder vería su obra de nuevo premiada: Über den Einfluss der schönen Literatur in den höheren Wissenschaften (1779), Von Einfluss der Regierungen auf die Wissenschaften und der Wissenschaften auf die Regierung (1780).

En su escrito Vom Geist der Hebräischen Poesie (1782) investiga la Biblia desde el punto de vista de la historia de la literatura y, dos años más tarde, comienzan a aparecer sus Ideen zur Philosophie der Geschichte der Menschheit, en la que plasma su idea del desarrollo de la humanidad como proceso ascendente. Esta obra supone una continuación de su concepción filosófica, histórica y lingüística, distanciándose del canon literario meramente nacional para el desarrollo cultural de un pueblo.

En el año 1787 Herder comienza a publicar su revista Adrastea, en la que publicará Der Cid (1802), un compendio de traducciones y reelaboraciones de romances españoles en torno a la figura de nuestro héroe. Con esta obra Herder retoma su interés por la literatura épica y heroica de cuño popular. Se ha visto en el abierto fragmentarismo de su obra la expresión de la continua reflexión y la tendencia del autor a la interdisciplinaridad, dado que en ella estudia los dos grandes temas del hombre y la historia desde múltiples perspectivas.

\section{Volkslieder alemanes y romances españoles: las fuentes de Herder}

Al interés innato de Herder por la poesía popular, la lengua, la historia y a su concepto de humanidad habría que añadir la aparición en Alemania desde mediados del siglo XVIII, de una serie de cancioneros, ante todo de origen inglés, como las

\footnotetext{
${ }^{2}$ Herder, Johann Gottfried. Zeitgenossen Goethes. http://www.kerber-net.de/literatur/deutsch/ drama/goethe/personen/herdetxt.htm
} 
Reliques of Ancient Poetry de Percy. En esta y otras obras semejantes Herder vio representado al pueblo germánico. Durante su estancia en Estrasburgo parece haber compartido esta afición por lo nacional con Goethe, con quien reunió unas catorce canciones de origen alemán. En 1771 la aparición de su ensayo sobre el origen de la lengua desencadenó tal entusiasmo entre sus lectores que en pocos meses apareció una gran cantidad de colecciones y traducciones de canciones populares.

El término Volkslied parece que fue utilizado por primera vez por Herder a quien, probablemente, debemos también el descubrimiento o la invención del género. La palabra Volk tiene para Herder dos características esenciales: 1. nación o cultura, portadora de una determinada forma de pensar con unas vivencias culturales e históricas determinadas, que se manifiestan en cada una de las lenguas y 2. conjunto de todas las gentes sencillas en oposición a los cultos y al Pöbel o populacho. Volk tiene para Herder una connotación sublime y noble casi idealizada. El segundo componente del compuesto alemán, Lied, se entiende como melodía o música que viene determinada por el contenido de la composición. Para Herder la esencia del Lied es la música, el canto, una sucesión melódica que expresa sentimientos o pasiones. El sentido del Lied se adquiere mediante la perfecta conjunción y síntesis entre la música y la expresión. De esta forma, la Volkslied es expresión del alma y de la esencia de un pueblo. Las gentes del pueblo aman sus canciones porque en ellas se refleja su propia naturaleza humana. Junto al interés etnológico, lingüístico e histórico del Volkslied, Herder ve en este género un elemento de cohesión y fomento de la conciencia nacional. La colección de Volkslieder de Herder pretende ser un reflejo de todo lo que la humanidad tiene en común, por lo que alcanza un sentido supranacional.

\subsection{Concepto y origen de los romances}

Entendemos por "romance" (Menéndez Pidal:1953) la producción épico-lírica española con origen en la tradición de los antiguos cantares de gesta, en leyendas o en los propios hechos. Según esta teoría, estos poemas épico-líricos se cantaban al son de un instrumento y no surgieron hasta finales del siglo XIV alcanzando su apogeo en los dos siglos siguientes. La intervención de muchos a través de un largo periodo de tiempo quedaría atestiguada por las diferentes versiones de un mismo romance y avalaría la amplia clasificación temática de estas composiciones. Sin embargo, la crítica del romanticismo (A. Durán: 1849) (Wolf y Hoffmann: 1856) opina que los romances son anteriores a los cantares de gesta basándose en su coincidencia temática y en algunas composiciones poéticas latinas con la misma métrica y rima. Formalmente el romance es una composición monorrima, asonantada en un octosílabo no y otro sí.

Por otro lado, el término romance, parece que no se conoció con este significado hasta mediados del siglo XV, como comenta Garci-Gómez ${ }^{3}$, aunque según otros

3 Eisenberg, D., Estudios cervantinos. http:// www.cervantesvirtual.com/servlet/SirveObras/ hisp/56882614200799372851191... 
autores, durante la segunda mitad del siglo XV y principios del XVI todavía no estaba claro su significado. Por otro lado, las citas de los teóricos (Domínguez Caparrós 1975: 481-482) sugieren que el término comenzó a usarse en el siglo XIX, cuando se identificó con el metro octosilábico.

Los romances españoles despertaron la curiosidad de otras literaturas europeas desde finales del siglo XVIII: Southey tradujo el Poema de Mío Cid (1814), Walter Scottt, Visión de Don Rodrigo (1811), Herder, el Poema de Mio Cid; también Schlegel, Grimm y Depping estudiaron y publicaron romances. Ya en el siglo XIX Wolf y Hoffmann publican Primavera y flor de romances (1856), mientras en Italia Giovanni Berchet y Pietro Monti realizan las primeras traducciones al italiano. Los primeros autores alemanes que se ocuparon de ofrecer versiones de romances en prosa fueron Gleim, Jacobi y Meinhardt.

Parece que el género y el término fueron introducidos en Alemania por J.W.L Gleim (1756) "Romanzen", en principio, como sinónimo de "Kunstballad". En el Sturm und Drang aparecieron recopilaciones y versiones de G.A.Bürger, Goethe y Schiller, pero fue Herder quien apeló al carácter popular asociado a la forma de estas composiciones. G.J.Herder, mediante la traducción congenial de los romances españoles abrió el camino para el florecimiento de este tipo de literatura durante el romanticismo, en el que participaron autores como L.Tieck, F. de la Motte-Fouqué, C. Brentano o H. Heine. Herder consiguió por primera vez hallar la forma adecuada en verso para la traducción de los romances españoles, que incluye en su colección de Volkslieder o Stimmen der Völker in Liedern, donde aparecen traducciones de romances nuevos (Góngora) y de romances viejos. El logro de Herder consiste en haber conseguido una sucesión de octosílabos trocaicos sin rima o con rima asonante. Herder opina que los romances españoles son los más antiguos y constituyen, por tanto, el origen de todos los demás. Una de las fuentes que utiliza Herder para su traducción muy bien podría ser La historia de las guerras civiles de Granada de Ginés Pérez de Hita, aparecida en París, en la tienda de Langelier en MDCLX.

\section{La confluencia cultural en Abenámar o Die Herrlichkeit Granadas}

Hemos seleccionado este romance por parecernos especialmente popular y muy representativo de la época a la que pertenece ya que en él se dan cita un rey cristiano y el moro Abenámar, "hijo de un moro y una cristiana cautiva". El romance está incluido dentro de los romances fronterizos, por lo que se trata "de un documento poético de la historia e intrahistoria de dos comunidades enfrentadas (la cristiana y la musulmana)" en tierras de Granada, al final de la reconquista. Los romances fronterizos y los moriscos nacen (Menéndez Pidal 1969:15-16), con la intención de informar al pueblo de los sucesos que ocurrían y preocupaban a la nación y de divulgar los encuentros y sucesos ocurridos en la guerra contra el reino moro de Granada. Según este autor, "los reyes no dejaban de valerse de los cantores popula-

\footnotetext{
${ }^{4}$ http://parnaseo.uv.es/Lemir/Revista/Revista7/Romances.htm
} 
res para propagar noticias: Enrique IV, en 1462, mandó hacer un romance sobre cierta campaña en tierras de Granada y encargó a los cantores de la Capilla Real que lo asonantasen". Por aquella época, en la Capilla de los Reyes Católicos se componían y cantaban otros romances sobre las últimas reconquistas granadinas" (Menéndez Pidal 1969:16). El romance de Abenámar se cree que fue escrito por un árabe en su lengua y después traducido, o bien por un moro con cultura latina que debió escribirlo directamente en castellano. Se ha llegado a esta conclusión por tratarse de textos con una base histórica y con claras reminiscencias orientales, lo que le otorga un carácter muy subjetivo, lírico y exótico. El romance se refiere a hechos ocurridos en 1431, por lo que pertenece a los últimos tiempos de la Reconquista.

El texto presenta un diálogo entre el rey Don Juan, quizá Juan II de Castilla, y el moro Abénamar, según Menéndez Pidal (Menéndez Pidal 1973: 33), Abenalmao (Yusuf Ibn Alahmar), noble granadino amigo de los castellanos, pero según otros (Torres Fontes: 1972-73, 225-256), un capitán que traicionó a Yusuf Ibn Alahmar, pasándose a su servicio. Otros autores (P. Benichou 1968: 68) opinan que es difícil identificar "al moro de la morería" por lo que piensa que muy bien podría tratarse de un interlocutor inventado frente al rey de Castilla cuya identidad tampoco precisa. Arnaldo Palacios cree que el nombre de Abelmao podría referirse a Yuça Aben Almao cuya interpretación castellana coincide con el árabe Ibn-al-Mawl o de AlAhmar, fundador de la dinastía nazarí de Granada cuyos descendientes podrían haberse llamado Aben-al-Ahmar que podría haber sido captado en castellano como Abenámar.

El romance fronterizo que nos ocupa parece sustentarse sobre la siguiente base histórica: Cierto príncipe árabe llamado Abenalmao debió ofrecer sus servicios al rey Juan II para obtener el gobierno de Granada una vez que la ciudad hubiera sido conquistada por los cristianos. Según testimonios históricos, el rey Juan II de Castilla (1405-1454) y el Condestable Álvaro de Luna siguiendo la política de Fernando de Antequera, decidieron reanudar la conquista de Granada atacando Alcalá la Real situada en la Vega de Granada en la primavera de 1431. Mientras tanto, en territorio árabe, Ridwan Bannigas salió en secreto de la ciudad para proponerle al rey de Castilla que instalara en el trono a un príncipe nasrí. Juan II, interesado en dividir a los príncipes nasríes, aceptó la propuesta apoyando a un pretendiente llamado en las crónicas castellanas Abenalmao.

Se conservan tres versiones del romance: una del Cancionero de Romances de Amberes, recogida también en la Silva I de Zaragoza (1550) y en la Rosa Española de Timoneda; otra segunda más larga, en la que aparece una situación inicial y unos versos al final que tratan de un ataque a Granada, y una tercera que aparece en las Guerras civiles de Granada (1595) de G. Pérez de Hita, la más conocida y la que utilizó Herder como base de su trabajo.

La estructura compositiva (Lara Garrido 1990: 37) "responde a una de las tres fases contempladas por la teoría tradicionalista en las gestas: el nacimiento como poesía noticiera, la reelaboración en variantes y la adición de temas secundarios, motivos descriptivos o novelización".

El romance comienza in media res con una apelación reiterada a Abenámar, en una conversación ya iniciada entre este personaje y el rey Don Juan, quien se refie- 
re a las "buenas señales" del día de su nacimiento y le conmina a decir la verdad, ya que los moros tenían fama de ser mentirosos. A ello responde Abenámar que es "hijo de un moro y una cristiana cautiva", que enseñó a su hijo a no mentir. El diálogo que sigue consiste en una serie de preguntas del rey Don Juan sobre diversos monumentos de Granada (La Alhambra, los Alijares, el Generalife, Torres Bermejas) a lo que Abenámar contesta ensalzando su valía y belleza. La parte final del romance en la que el rey muestra sus deseos de casarse con la ciudad de Granada, incluso de darle en dote a Córdoba y a Sevilla, ya conquistadas, recoge claramente la inspiración morisca. (Menéndez Pidal 1969: 224) "los poetas árabes llaman frecuentemente "esposo" de una región al señor de ella y de aquí el romance tomó su imagen de la "ciudad vista como una novia a cuya mano aspira el sitiador". Este mismo autor nos recuerda que esta imagen aparece referida a Magdeburgo en el Wallenstein alemán (1629), después de haber sido llevada por los soldados españoles a los Países Bajos y a Alemania. El poema acaba con un posible rechazo alegórico de la ciudad de Granada "casada soy, rey don Juan, casada soy, que no viuda; el moro que a mí me tiene muy grande bien me quería".

Presentamos a continuación la versión del romance español que aparece en Guerras Civiles de Granada (1569) de Ginés Pérez de Hita (García de Enterría 1997: 93-95) y, de forma paralela la versión de Herder'5

\section{ROMANCE DE ABENÁMAR y el rey don Juan}

\section{DIE HERRLICHKEIT GRANADA'S Spanisch}

\section{Ein Gespräch König Juans und Abenamars}

Abenámar, Abenámar

Moro de la morería, El día que tú naciste grandes señales había! Estaba la mar en calma, la luna estaba crecida moro que en tal signo nace no debe decir mentira.

Allí respondiera el moro bien oiréis lo que decía: "Yo te la diré, señor, aunque me cueste la vida, porque soy hijo de un moro y una cristiana cautiva; siendo yo niño y muchacho mi madre me lo decía

\begin{abstract}
Abenamar, Abenamar!
Mohr aus diesem Mohrenlande Jener Tag, der dich geboren, Hatte schöne grosse Zeichen: An ihm stand das Meer in Ruhe Und der Mond, er war im Wachsen; Mohr, wer unter solchen Zeichen Ward geboren, ...muss nicht lügen

Darauf erwiderte der Mohr ihm: (Wohl vernimmt es, was er sagte!) Nein, Sennor, ich lüge dir nicht, $\mathrm{Ob}$ es mir das Leben koste Denn ich bin Sohn eines Mohren Und einer gefangnen Christin! Und noch war ich Kind und Knabe Als die Mutter oft mir sagte:
\end{abstract}

${ }^{5}$ Herder, J.G., Volkslieder I- Erstes Buch.,"Die Herrlichkeit Granada's”. En Werke in zehn Bänden. Band 3. Volkslieder, Übertragungen. Hrsg. von Ulrich Gaier. Frankfurt: Deutscher Klassiker Verlag 1990, 108-109. 
que mentira no dijese que era grande villanía: por tanto pregunta, rey, que la verdad te diría" „Yo te agradzco, Abenámar aquesta tu cortesía.

¿Qué castillos son aquellos? altos son y relucían „El Alhambra era, señor, y la otra la mezquita los otros los Alixares labrados a maravilla. El moro que los labraba cien doblas ganaba al día, y el día que no los labra otras tantas se perdía. El otro es Generalife, huerta que par no tenía; el otro Torres Bermejas, castillo de gran valía" Allí habló el rey don Juan, bien oiréis lo que decía „Si tú quisieses, Granada contigo me casaría; daréte en arras y dote a Córdoba y a Sevilla "Casada soy, rey don Juan, casada soy, que no viuda; el moro que a mí me tiene muy grande bien, me quería.
Lügen, Sohn, das musst du nimmer!

Lüge, Sohn, ist niederträchtig.

Um deswillen frage, König,

Und ich will dir Wahrheit reden

Habe Dank, Mohr Abenamar

Dass du also höflich redest.

Was sind das für hohe Schlösser

Die dort stehen und wiederglänzen?"

Dies, Sennor, ist der Alhambra

Und das andre die Mesquita

Jenes sind die Alijares

Wurdenswürdig aufgeführet

Und der Mohr, der auf sie führte

Hatte Tags hundert Dublonnen,

Aber wenn er nicht am Bau war,

Musst' er Tages hundert zahlen

Jenes ist Gen'ralife

Ist ein Garte sonder Gleichen,

Diese Türme sind Bermejas,

Sind ein Schloss grosser Feste

Da erwiderte König Juan

(Wohl vernimm es, was er sagte!)

Wenn du es, Granada, wolltest

Wollt' ich mich mit dir vermählen,

Gäbe dir zur Morgengabe

Mein Cordova und Sevilla.

"Bin vermählet, König Juan,

Bin vermählet und bin nicho Witwe;

Mein Gemahl der Mohrenkönig

Liebt mich, als sein grosses Gut”.

\subsection{Estudio comparativo}

El romance consta de cuarenta y seis versos octosílabos con ritmo de timbre en la asonancia de los versos pares, ritmo de tono en las pausas ortográficas, versales y estróficas y ritmo de intensidad mediante la combinación del pie troqueo, pie dáctilo y mixto. La traducción de Herder reproduce este esquema métrico con diez estrofas de cuatro versos y una estrofa final de seis. Herder no logra reproducir fielmente la rima asonante en los pares, a pesar de sus intentos: Mohrenlande / Zeichen / Wachsen... quizá por eso optara por otra disposición de las estrofas: Ruhe / lügen; Wachsen / Zeichen; ihm / nicht... Para compensar esta pérdida hace uso de la aliteración, procedimiento poético tradicional en alemán: Kind und Knabe; Mutter oft...sagte; Hatte Tags hundert; Aber, wenn...Bau war; Garten...gleichen; Gäbe...Morgengabe.

A nivel fonético, debemos resaltar las intervenciones del rey ya que muestran mayor variedad tonal: en los v. 1-4 predomina la función apelativa y exclamativa 
con reiteración de vocativos y aliteración del sonido $\mathrm{m}$. En la segunda intervención del rey encontramos una estructura interrogativa seguida de una exclamación (v. 2324) y en la tercera, una propuesta de matrimonio introducida por una subordinada condicional y la promesa de una contrapartida si acepta (v. 39-42). La negativa de Granada aludiendo a su situación de mujer casada y el amor que le profesa su esposo va seguida de un silencio prolongado y enigmático que coincide con el final del romance. Por otro lado, las respuestas de Abenámar son correctas, detalladas, pero no exentas de orgullo. El narrador emplea fórmulas de introducción al diálogo de origen épico, mediante las que intenta captar la atención del público. Naturalmente, es en este terreno donde se dan las mayores divergencias entre la fonética del romance original y la versión traducidas por imperativos fonéticos y sintácticos de la lengua alemana que hacen casi imposible lograr el mismo efecto que en español: versos más largos, a veces, truncados en alemán. El tema del romance puede interpretarse como un requiebro amoroso del rey castellano y el rechazo justificado de Granada debido a compromisos anteriores.

La estructura narrativa muestra un doble diálogo en el que el rey cristiano se dirige primero, a Abenámar (v. 1-36) y después, a Granada (v. 37-56). El primer diálogo es verosímil: muestra el interés del rey por conocer la ciudad, mientras que el segundo, deseo de poseer, de conquistar Granada, entra de lleno en el plano de la irrealidad y está dotado de mayor lirismo. La estructura, por tanto, es ascendente.

Esta estructura narrativa también se ha conservado en ambas composiciones, tanto en la macroestructura como en la microestructura. En la macroestructura podemos destacar tres partes:

1. Diálogo del rey Don Juan y Abanámar (v. 1-20): diálogo introductorio con interferencia ponderativa del narrador, y contestación de Abenámar: El moro ha nacido en circunstancias prodigiosas por lo que no debe mentir (v. 1-8); interferencia ponderativa del narrador (v. 9-10); Respuesta del moro: el rey puede preguntarle pues su ascendencia es mixta y ha sido educado en la verdad.

2. Diálogo entre el rey y el moro (v. 21-36): Agradecimiento del rey Juan (v. 2124); Preguntas del rey sobre los castillos que se divisan; Contestación del moro: el Alhambra, la mezquita, los Alixares, Torres Bermejas (v. 25-36)

3. Interpelación del narrador (v. 37-38); interpelación galante del rey a Granada (v. 39-42). Negativa de Granada ya que pertenece a otro señor musulmán.

Como hemos mencionado, el romance comienza in media res y acaba con cierta brusquedad. En él oímos tres voces: la del rey, exclamativa, ponderativa con presencia de vocativos reiterados; la del moro, respetuosa, justificativa y orgullosa, con abundantes descripciones ponderativas y la del narrador dirigida a los oyentes que da paso a cada uno de los interlocutores del diálogo.

A nivel morfosintáctico hay que destacar la yuxtaposición de frases cortas (v.918) interrumpida por una subordinación de relativo (v. 2, 7, v. 17, 18, 20); la yuxtaposición de derivación descriptiva ("moro de la morería"); el encomio exclamativo de prodigios con estructura sintáctica similar, así como un quiasmo de sujeto verbo 
(v. 5-6: estaba la mar en calma/ la luna esta crecida). En la respuesta de Abenámar encontramos reiteración en "te la diré / la verdad le diría" (v. 12), repeticiones sinonímicas de niño y muchacho, anafóricas (v.17-18) y el tropos (v.18 "villanía"). En los verbos observamos cierta libertad en el uso de los tiempos ("relucía" por "reluce") o cierta oscilación entre el presente deíctico y el imperfecto que tienden a crear una atmósfera irreal entre el presente y un pasado mítico. En esta parte del romance las frases continúan siendo cortas y yuxtapuestas (v. 25, 27; 33, 35) alternando con subordinación sencilla y repetitiva: el otro produce un efecto de acumulación. Algunas palabras fluctúan como "aquesa / esa" (v. 22). En la parte final hallamos una subordinada condicional con empleo del subjuntivo (v. 39) que altera bruscamente la sencillez y el realismo del poema y capta la atención del público por su propio valor hipotético y la expectación ante la respuesta de Granada.

En el texto traducido observamos mayor frecuencia de subordinación que en español: subordinada temporal (v. 16), subordinación (v. 22, 31), así como reproducción de estilo directo en estilo indirecto (v.17). En las intervenciones del narrador se emplea el imperativo en lugar del futuro (v.10).

En otros tiempos verbales se ha sustituido el pretérito imperfecto de subjuntivo, típico de los romances, por el indicativo: "respondiera / erwiderte"; o por el presente histórico en la versión alemana: "era / ist"; "relucían / wiederglänzten"; "habló / erwidert"; "quería / liebt". Otras diferencias que afectan al uso de las formas verbales entre los dos poemas son las siguientes: la forma arcaica y literaria ward geboren, la reproducción del futuro de indicativo español por el imperativo alemán, oiréis / vernimm", o por el subjuntivo alemán, "darete / gäbe", el gerundio español siendo por el imperfecto con adverbio, "siendo / noch war"; y los subjuntivos españoles "dijese / lügen... das musst du"; "diría / will...reden"; "casaría / wollt' vermählen".

En cuanto al nivel léxico-semántico, destacamos la presencia de arcaísmos fluctuantes (v. 11: "aquesa" por "esa"), villanía por maldad, muy bien traducido por niederträchtig, al igual que las repeticiones sinonímicas niño y muchacho (v. 15) en las que la traducción al alemán las reproduce con aliteración Kind und Knabe, en el v. 34 encontramos perífrasis ponderativa y en los versos finales (v. 40-44), una reiteración de las palabras que constituyen el campo semántico de la alegoría ciudadnovia. En la respuesta de Granada podemos observar repeticiones anafóricas y sinonímicas con sentido metafórico (v. 43-44: "casada soy... que no viuda"). La respuesta final queda abierta, truncada y enigmática. Todos estos elementos comentados le otorgan al romance abundantes elementos líricos y dramáticos alejándolo claramente de los elementos de la épica.

Las palabras culturales han sido fielmente traducidas, hasta donde es posible: Mohrenlande, gefangen, niederträchtig, Morgengabe, o incluso reproducidas Sennor, pero, lógicamente pierden la connotación que les otorga la fonética española. Debemos destacar también la libertad del traductor en el v. 36. Por otro lado, encontramos una especificación aclaratoria en los v. 45 "Mein Gemahl, der Mohrenkönig / El señor que a mí me tiene", y v. 46 "Liebt mich als sein Grosses Gut / muy grande bien me quería", con cambio de tiempo verbal.

En el plano de la retórica hallamos abundantes anáforas en la descripción de Granada con enumeración retórica (v. 25-28; 33-36), el hipérbaton "altas" y "relucir" (v. 24). En la extensa y equilibrada enumeración se hace destacar cada elemento des- 
crito con anáforas (v. 26, 27, 33, 35) que producen un efecto acumulativo. Es de destacar la hipérbole del verso 29, la personificación metafórica (v. 39-46) y la repetición anafórica y sinonímica (v. 43, 44)

La diferencia fundamental de la versión de Herder con respecto al original afecta al título que se centra en la personificación de Granada. Probablemente, esto fue lo que más le llamó la atención junto con la base histórica del final de la reconquista española y el carácter exótico que proporciona la conversación entre un rey cristiano y un moro. Esta es la razón por la que eligió un título que destaca el final del romance "Die Herrlichkeit Granada 's" y un subtítulo que adelanta la estructura dialogada del romance: "Ein Gespräch König Juan und Abenamars".

El resto de las diferencias con respecto al original afectan, casi exclusivamente, a cuestiones externas como la disposición del poema en estrofas de cuatro versos, los paréntesis en las intervenciones del narrador, la puntuación y dos notas explicativas a pie de página referidas a la Alhambra y el Generalife, necesarias para el lector alemán de la época.

\section{Conclusión}

El interés de esta temprana versión estriba en la sensibilidad mostrada por Herder para reconocer en este romance una estilización simbólica y poética de la convivencia entre árabes y cristianos de la España medieval, personificada en la ciudad de Granada. De esta forma, la traducción del romance español al alemán viene a mostrar una síntesis de los grandes temas que preocupan a Herder: la historia, la humanidad y el lirismo de la lengua, portadora de los sentimientos de un pueblo.

\section{Referencias bibliográficas}

Benichou, P., «Abenámar», en: Creación poética en el romancero tradicional. Madrid 1968. Daten der deutschen Literatur. Johann Gottfried Herder http://874/homepage/herder.htm Das Volkslied bei Herder. http://www.nthuleen.com/papers/984Volkslieder.htm Del Moral, R., Diccionario práctico de comentario de textos. Madrid: Verbum 1995.

Domínguez Caparrós, J., «Contribución a la historia de las teorías métricas en los siglos XVIII y XIX», Revista de Filología Española Anejo 92 (1975).

Döhl, R., Romanzenrezeption im 18. Jahhundert. http://dolch.netzliteratur.net/mirror_uni/ballade_ $10 \mathrm{~b} . h \mathrm{htm}$

Durán, A., Romancero general. Madrid: Rivadeneyra 1849-51.

Eisenberg, D., Estudios cervantinos, en: http://www.cervantesvirtual.com/servlet/SirveObras/hisp/5688261420079937285191

Frenzel, H. A. y Frenzel, E., Daten deutscher Dichtung. Chronolgischer Abriss der deutschen Literaturgeschichte. Bd.1. München: dtv 1977.

García Enterría, M.C. (ed.), Romancero Viejo. Madrid: Castalia 1997.

Herder, J.G., Volkslieder I. Erstes Buch: Die Herrlichkeit Granadas, en: Werke in zehn Bänden. Bd. 3. Volkslieder, Übertragungen. Hrsg. von Ulrich Gaier. Frankfurt: Deutscher Klassiker Verlag 1990. 
Herder, Johann Gottfried, Zeitgenossen Goethes. http:// www.kerber-net.de/literatur/deutsch/ drama/goethe/personen/herdertxt.htm

Herder, JohannGottfried/Biographie_Zeno.org http://www.zeno.org/literatur/M/Herder+ Johann+Gottfried/Biographie http://lexikon.meyer.de/meyers/Romanze http:// parnaseo.uv.es/Lemir/Revista/Revista7/Romances.htm

Killy W. (ed.) Literaturlexikon. Autoren und Werke deutscher Sprache. Bd.5. Gutersloh / München: Bertelsmann 1988.

Lara Garrido, J., «Introducción», en: Alvar, M., Granada y el Romancero. Granada 1990.

Menéndez Pidal, R., Estudios sobre el romancero. Madrid: Espasa Calpe 1973.

Menéndez Pidal, R., Flor nueva de romances viejos. Madrid: Espasa Calpe 1969.

Menéndez Pidal, R., Romancero Hispánico. Madrid: Espasa Calpe 1953.

Negro Pavón, I. (ed.), Johann Wolfgang Goethe. Escritos políticos. Madrid: Editora Nacional.

Torres Fontes, J., La historicidad del romance Abenámar, Abenámar, en: Anuario de Estudios Medievales, 8 (1972-1973), 225-256.

Wolf y C.Hoffmann, Primavera y flor de romances. Berlin: A. Asher y Comp.: 1856.

Zaremba, M. Johann, Gottfried Herder-Prediger der Humanität. Vortrag am 12. September in Wieland Museum Biberach anlässlich von Herders 200 Todesjahr und der Buchveröffentlichung. http://www.webersberg.de/gespraech/michael-zaremba-erder.html 